American Journal of Environmental Sciences 2 (1): 10-14, 2006

ISSN 1553-345X

(C) 2006 Science Publications

\title{
Agricultural Waste Management Extension Education (AWMEE) The Ultimate Need for Intellectual Productivity
}

\author{
Iraj Malek Mohammadi \\ College of Agriculture, University of Tehran, Karaj, Iran
}

\begin{abstract}
Extension education is significant range of fields like Agriculture, Natural Resources, Environmental and Bio Diversity Conservation, Rural Development, Home Management Skill Development, Disaster Management, Waste Management, Value Adding Management. Among them, waste management extension is highly significant because of the millions of tons of annual waste in vegetal, animal, environmental and natural resources products as well as millions of hectors of land degradation. Waste management extension deals with raising the efficiency and productivity of the agricultural industry, intellectually and/ or economically. Both producers and consumers should be fully aware of the mechanism by which waste in agricultural commodities diminishes to a considerable level. In agriculture, knowledge and decision-making capacity determine how production factor (i.e. oil, water, capital, chemicals, etc) are utilized. Agricultural extension is a focal issue in formulating and disseminating knowledge and helping farmers to be competent decision makers. This article is designed to provide a theoretical and conceptual framework for "agricultural" extension (i.e. mutual agreement between producers and consumers in comprising agricultural waste management) to respond to the world-wide expectations for extension to raise agricultural productivity, food production, bio- safety as well as environmental and bio-diversity conservation. Literature review, content analysis and modeling through utilizing contingency tables were employed to conduct the study. Different experiences in this regard have been collected and results show that the greater the use of AWMEE, the less agricultural waste, the higher the agricultural productivity and lower the land degradation.
\end{abstract}

Key words: Agricultural waste, agricultural waste extension education, intellectual productivity

\section{INTRODUCTION}

Globalization in the agricultural industry is increasingly competitive. In response, extension should be capable of tackling a diversity of challenges in: effectively linking more clienteles to domestic and international markets ${ }^{[1]}$; promoting environmental conservation $^{[2]}$ and natural resources management; enhancing nanotechnology, biotechnology and biodiversity; securing food safety, food security ${ }^{[3]}$ and food-sufficiency, far exceeding of its traditional role in transferring technology.

International, regional and even national global consultations recommend continuous revision, updating, upgrading and advances in national extension policies, strategies, goals, responsibilities and institutional restructuring extension plans as are embodied in different country development plans around the world. These changes should be programmatic and addressed to the needs and potentiality of each country.

Although extension may be conceived primarily as a way of enhancing the agricultural sector within the country, international expectations lead us towards involving some complementary enterprises in developing an extension model.

In agriculture, knowledge and decision-making capacity determine how production factors (i.e. soil, water and capital) are utilized. Agricultural extension is central formulating and disseminating knowledge and helping farmers to be competent decision-makers. Therefore, extension plays an important role in most agricultural development projects including Agricultural Waste Management Extension Education (AWMEE).

Agricultural Waste Management Extension Education is part of a system of actors who help farmers to make the most appropriate decisions, rather than influencing or intervening in their decisions in increasing farming efficiency and/or making decisions for them. It includes, among others, agricultural researchers, political authorities, farmer organizations, non-governmental organizations (NGOs), farmer training centers and the media. These agents assume the functions of research, information dissemination, training and so on.

Why Agricultural Waste Management Extension? Consider the sheer quantity of foodstuffs we shop for

Corresponding Author: Iraj Malek Mohammadi, College of Agriculture, University of Tehran, Karaj, Iran, Tel: +982612238293, Fax: +982612818709 
each week. How much of this do we actually consume? And how much do we throw away? The bulk of purchases any household makes on a sustained basis comprises of food. It is also what many of us waste the most, as indicated by the fact that about half the municipal solid waste making its way to landfills consists of organic materials, largely food.

This is tragic in a world in which 840 million people remain undernourished and six million children under the age of five die of hunger and malnutrition each year. There couldn't be stronger ethical and humanitarian reasons for curbing food wastage. There are compelling environmental reasons as well from its production to disposal, considering the land, energy, chemical fertilizers, water, pesticides and more, used to grow crops. In addition, the issue of storage, transportation, processing, packaging, refrigeration and further transportation must be considered. Each step requires energy, money and infrastructure.

According to an estimate, an average of about 10 units of non-renewable fossil fuel energy is needed to put one unit of food energy on the table. And in considering of water, globally, some 70 percent of all water that is pumped from underground or diverted from rivers is used to produce food. Thus, food wastage implies water and energy wastage as well. In many countries, agriculture is the biggest source of water pollution. Voluminous amounts of dumped food also have to be cleared regularly leading to further energy consumption and contamination of air, land and water.

The situation is compounded when livestock products are wasted. As incomes rise, people consume more grain, but also indirectly in the form of meat, eggs, milk, cheese and other products of grain-eating, domesticated animals and birds. Globally, meat production has increased 60 percent over the past four decades and indications are that in the next five decades, the greatest impact on the environment from farming will likely come from increased meat consumption.

It takes between three and $10 \mathrm{~kg}$ of grain to produce one $\mathrm{kg}$ of meat. Soil erosion and fertility loss, water depletion and pollution with pesticides and nitrates from fertilizers, oxygen depletion in coastal and inland waters from agricultural runoff are some of the consequences of industrial agriculture in practice today.

Evidently, food waste is a vital issue that, unfortunately, does not get enough media coverage, even though it directly relates to the level of understandings and attitudes of all of us. The hectic pace of development in the last 20 years has so commercialized our society that people have forgotten the proper, ethical way of conserving food. Although, people are living comfortably in many countries around the world and food is readily available at reasonably prices, but that does not mean we should waste it.

Consequently, there are many reasons for implementing Agricultural Waste Management Extension world wide. The following are the most common justifications:
* The agricultural sector demands more complex changes to remain efficient.

* Continuous emergence of production and processing deficiencies.

* Integration of agriculture and industry

* Continuous expansion of food poverty and commitment of governments to poverty obstacle abolition.

* Rapid population growth; increasing food and fiber demands

* Productivity concentration

* Market safety and beneficiary

* Increasing demand on improving food safety, sufficiency and availability among nations

* Poverty abolition through agricultural literacy, technological and socio-economical transformation

* Natural cycle of human and technology erosion

* All of these should be considered as for establishing a new vision of extension that favors of food security, safety and sufficiency. The AWMEE strategy can be summarized in the following words ${ }^{[4]}$ :

* Improve interaction among actors within the Agricultural Knowledge and Information System (AKIS) (i.e. farmers, researchers, political authorities, farmer organizations, nongovernmental organizations, farmer training centers and the media).

* Assist farmers to have optimum access to any information that could help them to reduce and enhance their economic situation.

* Create alternative structures that are both politically and economically sound, viable and sustainable.

* Help farmers respond to the demands of internationalization, liberalization and self sufficiency.

* Enhance the role of women in home economic and food waste prevention

* Improve food security

* Abolish poverty obstacles, i.e., informational poverty, intellectual poverty and economic poverty Is AWMEE a discipline? Extension is a discipline in its own right because it is a particular branch of behavioral scientific knowledge underpinned by theory that explains scientific observations which can be tested by experiment or observation. As such, extension needs its own disciplined actors (i.e. scientists, researcher, evaluator, educator, experts, agents and field workers).

As stated earlier, the primary goal of AWMEE is to assist urban and rural families and natural resource beneficiaries to adapt their production, consumption and marketing strategies to rapidly changing cultural, social, political and economic conditions so that they can, in the long term, shape their lives according to their personal preferences and those of the community.

The task of extension, thus, is to improve interactions among actors within the Agricultural Waste 


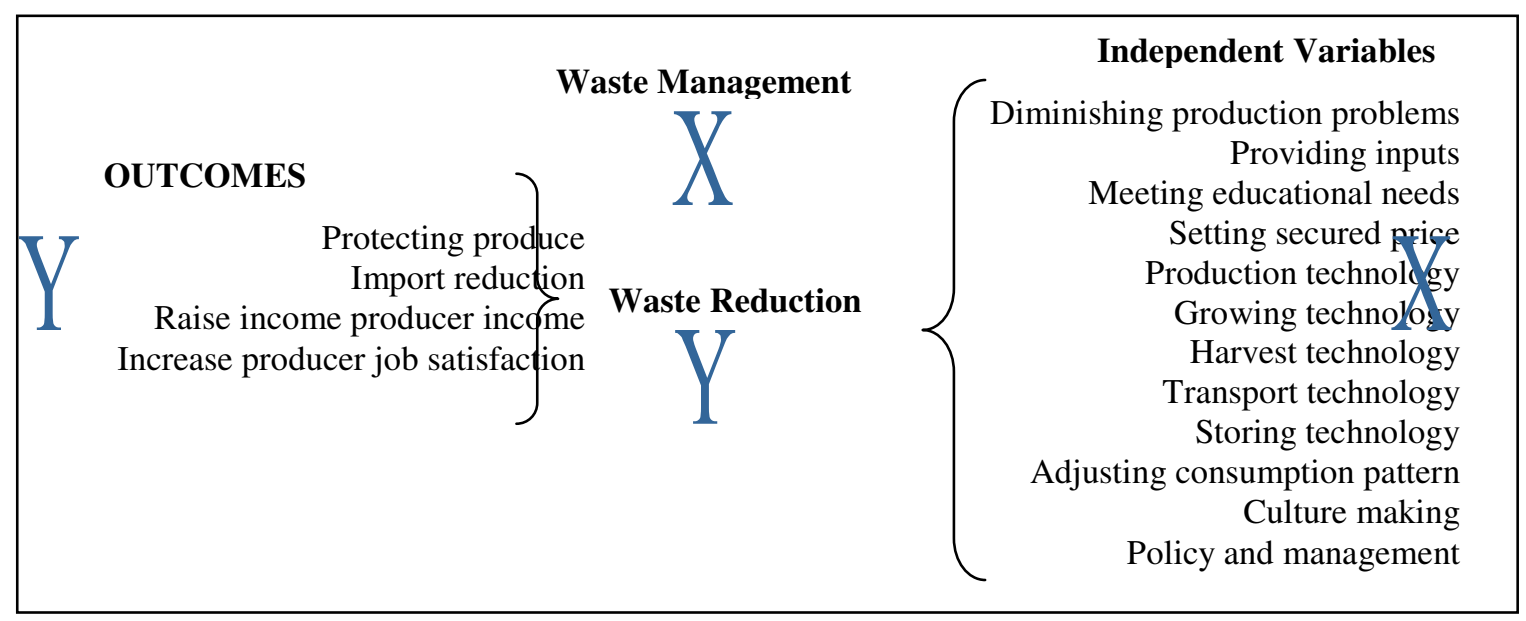

Fig. 1: Variables in AWMEE study

Management System (AWMS), so that all clients have optimum access to any information that could help them enhance their cultural, economic and social situation. Extension is, in the first instance, "agreecultural" development between actors in the AWMS. This mediating function focuses on improving those relationships that promise to be most beneficial to the economic development of clients.

Agricultural Waste Management Extension Education deals with almost all aspects of agriculture and natural resources demanding knowledge and understanding. In any aspects of human resources development and human resources capital development, extension has an active and determinant role to play. AWMEE specifically has a role in a widespread range of activities such as agriculture, natural resources, environmental conservation, rural development, home management Skill development, disaster management, waste prevention and value adding management.

Purpose: The main purpose of this research is to determine how Agricultural Waste Management Extension Education (AWMEE) can diminish agricultural waste and conserve the environment. This article was written to provide a theoretical and conceptual framework for "agreecultural" extension (i.e. mutual agreement between producers and consumers in comprising agricultural waste management) in respond to the world-wide expectations of extension to raise agricultural productivity, food production, bio- safety as well as environmental and bio-diversity conservation.

\section{MATERIALS AND METHODS}

This research employed an applied-descriptive research design due to the application of the findings to the interested policy-makers and research designers. Theoretical study, literature review and content analysis were used to conduct the research.
Another method applied in this study was conceptual modeling of the theoretical findings. According to the model developed in this part of the study agricultural waste was considered as an irrational use of human resources (i.e. providers, producers and consumers). This behavior is reflective of their technical illiteracy (i.e. educational needs) and lack of technological conception, in the absence or abuse of agricultural waste management extension. The behavior can be rationalized by investigating and fulfilling the professional needs of agricultural human resources.

A meta-analysis method was required to analyze the role of each of the components in the agricultural waste equation, due to the many factors that contribute toward creating agricultural waste. In the first amalgam equation, waste is considered the dependent variable and personal, professional and economical characteristics of producers, processors and consumers as well as components of the national policy are considered independent variables. In the second equation, Agricultural Waste Management Extension Education is considered as the independent.

\section{RESULTS AND DISCUSSION}

There are several groups of operators and beneficiaries involved in fulfilling AWMEE policies, strategies and goals. They include extension experts, scientists, specialists, administrators, field agents, producers, processors and consumers. AWMEE may be called on to provide Zero Emission Waste (ZEW) by preventing agricultural lose to waste and waste to lose (Fig. 2).

Results indicate that waste (in terms of product lose) is an "irrational behavior" in the professions. This non-intellectual behavior is inevitable in the absence of proper education. We need to establish adequate managers and expert agents to guide the producers, purchasers and consumers in the most appropriate ways 


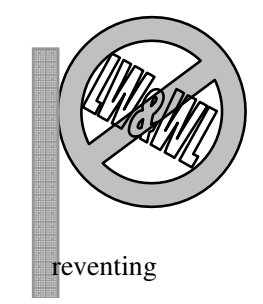

Lose to Waste \& Waste to Lose

Fig. 2: Conceptual model for preventing lose to waste and waste to lose

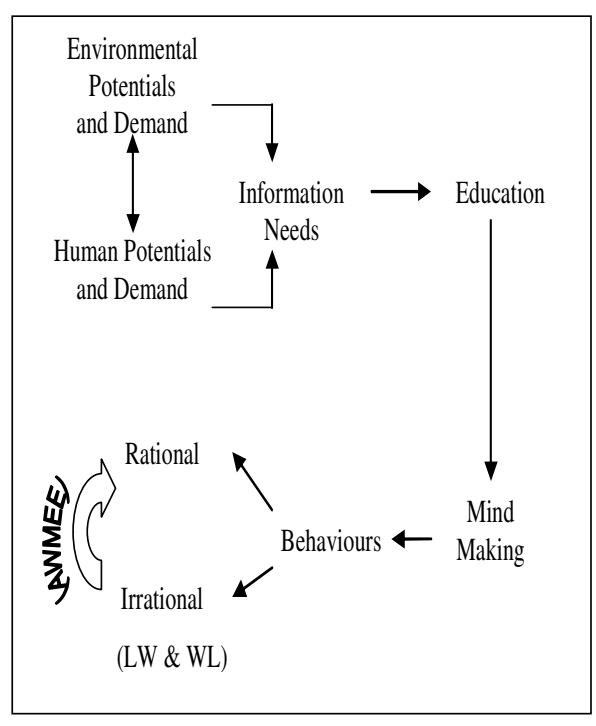

Fig. 3: Placement and role of extension education in behavior cycle ${ }^{[5]}$

of using products with the least amount of waste. Accordingly, we need to establish Agricultural Waste Management Extension Education at the B.Sc. and M.Sc. levels in Agricultural Faculties, as a joint venture with the Faculties of Educational Studies, Home Management, Home Economics and others.

According to the model developed in this part of the study (Fig. 3) agricultural waste was considered as an irrational behavior of agricultural man power, i.e., producers, processors and consumers. This behavior can be recognized, in turn, as the effect of a low level of functional literacy (i.e., educational needs) and lack of technological conception, in the absence or abuse of agricultural waste management extension. This behavior can be rationalized by investigating and fulfilling the professional needs of agricultural human resources.

As shown in Fig. 3, there are at least three major factors influencing waste in agriculture including: environmental potentials and demands; human

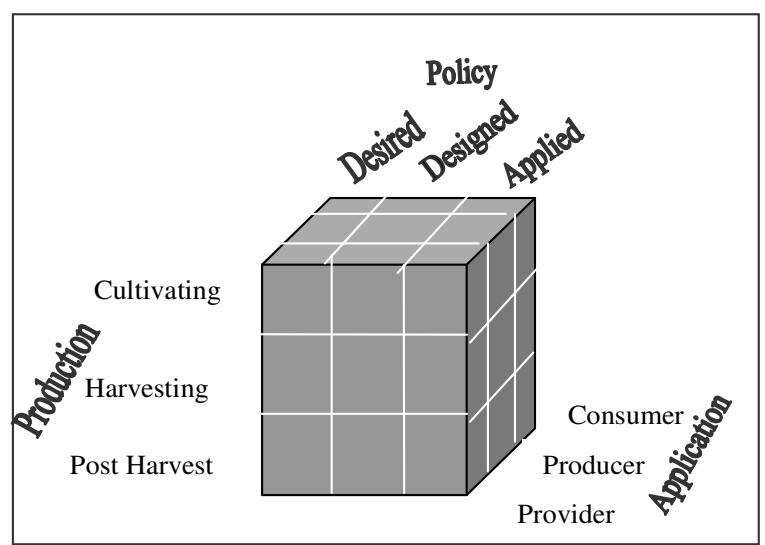

Fig. 4: Multi-dimensional production process

potentials and demands; information needs; education; mind set; behavior; rationale; and extension education to change irrational behavior (waste) to rational behavior. Along with these factors there are still other major key elements that are highly influential in either creating or in preventing agricultural waste. This wellknown factor is agricultural policy. This policy consists of three parts:

1. Desired policy, which is the major concern of the politicians, but there is no guarantee that they will be welcomed by administrators suppliers due to their level of possibility.

2. Designed policy, which is the major part of the desired policy that can be performed by the administrators regarding the circumstances.

3. Applied policy, consisting of that part of the designed policy that can be followed by providers, producers and consumers based on their real possibilities.

Application includes those who apply techniques and methods of producing and/or utilizing commodities in the agricultural industry.

Providers are those who prepare farm inputs and market facilities to produce and supply agricultural products. Producers are identified as those who use agricultural imputes to produce, change, reshape and process agricultural products. Consumers are those who use agricultural products to fulfill their own vital needs. Production consists of different phases of manipulating inputs to produce agricultural products in at least three major categories including:

1. Cultivation includes all plantation processes such as: preparing land; plowing; leveling; seeding; irrigating; fertilizing; and growing.

2. Harvesting process consists of all activities dealing with gathering products (grains, cereals, fruits, vegetables) and by-products. 


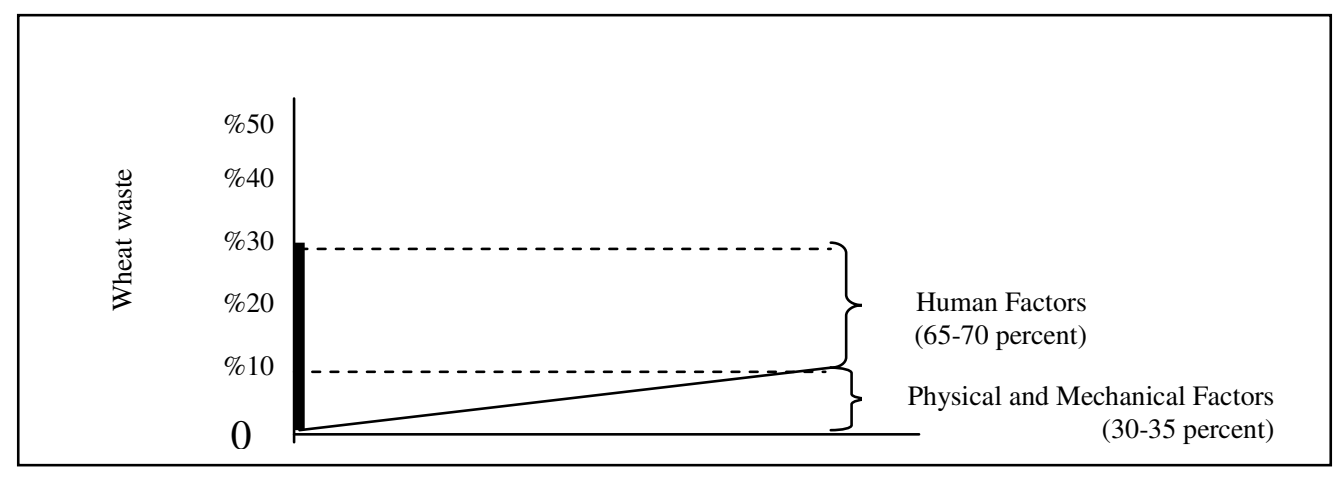

Fig. 5: Role of human and physical and mechanical factors in wheat waste ${ }^{[i \mathrm{ibid}]}$

3. Post-harvesting includes storing, processing, transporting and marketing.

Comparing human factors with physical and mechanical factors in agricultural waste indicates that human factors (social, cultural, economical, professional, etc.) were involved in wheat lose and waste twice as more than mechanical and physical (Fig. 5) ${ }^{[6] .}$

\section{CONCLUSION}

Agriculture and natural resource beneficiary are two of the top world-wide industries. These industries are facing loses as a consequence of irrational behavior of the technically illiterate found through the world. To prevent disastrous waste, human deficiencies in the agricultural industry should be addressed in the most appropriate way. To address wastage in an effective manner, the value of food should be instilled in the minds of young and old. To do so, Waste Management Extension Education should be enhanced as a worldwide "Care and Share" movement towards diminishing agricultural lose to the lowest possible extent and recycle to prevent more lose toward achieving zero emissions in the long term. In other words, prevent lose to waste and waste to lose. Finally, it can be concluded that:

* Establishing AWMEE in an interdisciplinary (agricultural, natural resources, environmental studies and human studies) department at the undergraduate level to train capable agents and at the graduate and post-graduate levels to train qualified experts and researchers will help waste management development to acquire more intellectual production and a cleaner greener Earth.

* Arranging an annual international conference will also help to guide AWMEE's promotion and progress in attending countries. In addition, conducting research projects in AWMEE will help to determine the role of different factors in agricultural lose and waste and achieve greater control over them, toward reducing waste in the long term.

\section{REFERENCES}

1. Farrington, J., 1998. Organizational Role in Farmer Participatory Research and Extension; Lessons for the last decade. MANAGE-ODI, National Research Perspective, No: 27.

2. Sulaiman, R. and A. Hall, 2004. Extension policy at the national level in asia. in new directions for a diverse planet. Proc. 4th Intl. Crop Science. Brisbane, Australia, Sep. 26-Oct 1.www.irandaily.com/1383 /2092/ html/focus.htm $<$ http://www.iran-daily.com/1383 /2092/ html/focus.htm. Visited March, 12, 2006.

3. Rivera, W. and K. Qamar 2003. A new extension vision for food security, challenge to change. sustainable development department. Food and Agricultural Organization of the United Nations. Rome, Italy.

4. Mohammadi, M.I., 2005.Towards universal agricultural extension paradigm: case study agricultural extension system in AIM Countries (Australia, Iran and Malaysia). Institute for Agricultural Extension. University Putra Malaysia (UPM), Serdang, Selangor Darul Ehsan, Malaysia.

5. Mohammadi, M.I., 2005. Extension approaches to reducing wheat waste in Iran. Research report. University College of Agriculture and Natural Resources, University of Tehran. Karaj, Iran.

6. Mohammadi, M.I., 2006. Factors influencing wheat waste in Islamic Republic of Iran. Proc. Intl. Conf. Agricultural Waste Management. University Putra Malaysia. Malaysia, Mar. 21-23. 